\title{
Kinetics of dodecanedioic acid and effect of its administration on glucose kinetics in rats
}

\author{
BY ALESSANDRO BERTUZZI ${ }^{1}$, GELTRUDE MINGRONE ${ }^{2}$, ANDREA DE GAETANO ${ }^{3}$, \\ ALBERTO GANDOLF ${ }^{1}$, ALDO V. GRECO ${ }^{2}$ AND SERENELLA SALINARI $^{4}$ \\ ${ }^{1}$ Istituto di Analisi dei Sistemi ed Informatica del CNR, Viale Manzoni 30, 00185 Roma, Italy \\ ${ }^{2}$ Istituto di Clinica Medica, Università Cattolica del Sacro Cuore, Largo A. Gemelli 8, 00168 Roma, Italy \\ ${ }^{3}$ Centro di Studio per la Fisiopatologia dello Shock del CNR, Università Cattolica del Sacro Cuore, \\ Largo A. Gemelli 8, 00168 Roma, Italy \\ ${ }^{4}$ Dipartimento di Informatica e Sistemistica, Università di Roma 'La Sapienza', Roma, Italy
}

(Received 30 April 1996 - Revised 26 September 1996 - Accepted 17 October 1996)

\begin{abstract}
Dodecanedioic acid (C12), a saturated aliphatic dicarboxylic acid with twelve $\mathbf{C}$ atoms, was given as an intraperitoneal bolus to male Wistar rats, with the aim of evaluating $\mathrm{C12}$ suitability as an energy substrate for parenteral nutrition. The $24 \mathrm{~h}$ urinary excretion of $\mathrm{C12}$ was $3.9 \%$ of the administered dose. $\mathrm{C12}$ kinetics were investigated by a one-compartment model with saturable tissue uptake and reversible binding to plasma albumin. The analysis of plasma concentration and urinary excretion data from different animals yielded the population means of the kinetic parameters: renal clearance was $0.72 \mathrm{ml} / \mathrm{min}$ per $\mathrm{kg}$ body weight (BW) (much smaller than inulin clearance in the rat), and maximal tissue uptake was $17.8 \mu \mathrm{mol} / \mathrm{min}$ per $\mathrm{kg} \mathrm{BW}$ corresponding to $123.7 \mathrm{~J} / \mathrm{min}$ per $\mathrm{kg} B W$. These results encourage the consideration of $\mathrm{C12}$ as a possible substrate for parenteral nutrition. To investigate the effect of $\mathrm{C12}$ administration on glucose kinetics, two other groups of rats, one treated with an intraperitoneal bolus of $\mathrm{C12}$ and the other with saline, were subsequently given an intravenous injection of $\mathrm{D}-\left[\mathrm{U}-{ }^{14} \mathrm{C}\right]$ glucose in a tracer amount. Radioactivity data of both control and C12-treated rats were analysed by means of a two-compartment kinetic model which takes into account glucose recycling. The estimates of glucose pool size $(2.3 \mathrm{mmol} / \mathrm{kg} \mathrm{BW})$ and total-body rate of disappearance $(82.1 \mu \mathrm{mol} / \mathrm{min}$ per $\mathrm{kg} \mathrm{BW})$ in control rats agreed with published values. In C12treated rats, the rate of disappearance appeared to be reduced to $36.7 \mu \mathrm{mol} / \mathrm{min}$ per $\mathrm{kg} \mathrm{BW}$ and the extent of recycling appeared to be negligible.
\end{abstract}

Dodecanedioic acid: Glucose: Parenteral nutrition

Many studies have been performed on the synthesis and fate of dicarboxylic acids (DA) in living organisms since the paper of Verkade \& Van der Lee (1934). These authors showed that, after the administration of triundecylin to two healthy volunteers, a considerable amount of undecanedioic acid, the corresponding dicarboxylic acid with eleven $\mathrm{C}$ atoms, was excreted in the urine. Therefore, they hypothesized that the terminal methyl group of triundecylin underwent oxidation leading to the formation of a carboxylic group. Subsequently, the authors called this kind of oxidation $\omega$-oxidation. Although the results on the quantitative importance of $\omega$-oxidation in the oxidation of fatty acids appear to be quite confusing (Wada \& Usami, 1977; Bjorkhem, 1978), there is consensus on the fact that when the $\beta$-oxidation route is impaired, $\omega$-oxidation becomes a very important metabolic pathway for oxidation of fatty acids (Lindstedt et al. 1976; Mortensen \& Gregersen, 1981).

Dicarboxylic acids with chain lengths shorter than or equal to twelve $\mathrm{C}$ atoms are $\beta$ oxidized in both mitochondria and peroxisomes (Pettersen \& Aas, 1973; Leighton et al. 
1989). Odd-chain DA are split to acetyl-CoA and, as a terminal product, to malonic acid, which is not further oxidizable and is the starter of fatty acid synthesis. In contrast, evenchain DA can be completely oxidized, since they produce acetyl-CoA and succinyl-CoA which are completely oxidized in the Krebs cycle. In addition, succinyl-CoA is a gluconeogenic substrate (Wada \& Usami, 1977; Kou \& Tserng Shiow-Jen, 1991). DA have been investigated as possible alternative fuel substrates for parenteral nutrition (Mingrone et al. 1989, 1991; Bertuzzi et al. 1991; Greco \& Mingrone, 1995).

Previously, we reported that the continuous intravenous infusion of disodium sebacate (a DA with ten $\mathrm{C}$ atoms) caused a significant reduction of glucose uptake in normal and obese individuals and subjects with insulin-dependent diabetes mellitus (Raguso et al. 1994). The glucose-sparing effect of sebacate seemed to be directly exerted at the intracellular level, because insulin secretion was not stimulated (no modifications of plasma C-peptide values were shown), nor was sebacate plasma clearance influenced by hyperinsulinaemia.

Dodecanedioic acid (C12) is a saturated aliphatic DA with twelve $\mathrm{C}$ atoms which, contrary to shorter chain DA, presents a very low urinary excretion (Mingrone et al. 1994; Bertuzzi et al. 1995). The aim of the present study was to investigate the tissue uptake of C12 and the effect of its acute administration on glucose kinetics.

\section{MATERIALS AND METHODS}

\section{Experimental protocol}

Three groups of male Wistar rats (average body weight (BW) $200 \mathrm{~g}$, fasted for about $8 \mathrm{~h}$ ) were injected intraperitoneally with $0.8 \mathrm{mmol} / \mathrm{kg} \mathrm{BW}$ of $\mathrm{C} 12$ (in the form of the disodium salt) as a bolus ( $n 35$, group $\mathrm{A}$, and $n 35$, group $\mathrm{B}$ ), or of an equal volume of physiological salt solution ( $n 30$, group C). Five additional rats, injected with $\mathrm{C} 12$ as described earlier, were allocated to individual metabolic cages in order to collect $24 \mathrm{~h}$ urine samples.

Blood samples were drawn by cardiac puncture, one for each animal of group A, at different times after the bolus in the range from 5 to $90 \mathrm{~min}$. The animals were then anaesthetized with diethyl ether and immediately killed by cervical dislocation. No anaesthetic was used before any experimental manoeuvre. All rats in the B and C groups received, immediately after injection of $\mathrm{C} 12$ or saline, an intravenous bolus (tail vein injection) of $\left.139 \mathrm{kBq} \mathrm{D-[U-}{ }^{14} \mathrm{C}\right]$ glucose (Amersham, Bucks; specific activity $11248 \mathrm{MBq} /$ mmol). Blood samples were drawn, in the same fashion as in group $A$, between 5 and $120 \mathrm{~min}$ after the bolus. Heparinized blood samples were immediately centrifuged at $4000 \mathrm{~g}$ and plasma was frozen at $-20^{\circ}$ until analysis.

\section{Analytical methods}

To measure the tracer concentration in plasma, $0.5 \mathrm{ml}$ plasma was put in a glass test-tube cooled on ice. Ice-cold $700 \mathrm{ml} / \mathrm{l}$ acetone in water $(4 \mathrm{ml})$ was added to the tube and stirred gently. The sample was centrifuged at approximately $6000 \mathrm{rev} . / \mathrm{min}$ for $10 \mathrm{~min}$. Plasma extract was dried in a GyroVap apparatus (Howe model GV1, Gio. De Vita, Rome, Italy) operating at $60^{\circ}$, coupled with a vacuum pump and a gas trap FTS System (Stone Ridge, New York, USA). The extract was resuspended in acetone--water $(4: 1, \mathrm{v} / \mathrm{v})$ and deposited on silica gel Fluka G plates $(200 \times 200 \mathrm{~mm})$ with binder for TLC, impregnated with $0.2 \mathrm{M}$ sodium acetate. The layers were dried for $24 \mathrm{~h}$ at room temperature and activated at $110^{\circ}$ for $1 \mathrm{~h}$. Extracts were eluted using acetone-water $(9: 1, \mathrm{v} / \mathrm{v})$ as the solvent system. With this method, the $R_{F}$ of glucose was equal to $25 \%$. The spots were detected by 
naphthoresorcinol- $\mathrm{H}_{2} \mathrm{SO}_{4}$ reagent, and those corresponding to glucose were scraped out of the plates and put in vials, adding $0.5 \mathrm{ml}$ water and $10 \mathrm{ml}$ Insta-Fluor ${ }^{\mathrm{TM}}$ (Packard, Downers Grove, IL, USA). ${ }^{14} \mathrm{C}$ radioactivity was measured by a $\beta$-scintillation counter (Model 1600TR Canberra-Packard, Meriden, CT, USA). Quenching was checked by the internal standard method. In order to measure the total recovery of $\mathrm{D}-\left[\mathrm{U}-{ }^{14} \mathrm{C}\right] \mathrm{glucose}$, amounts ranging from $33.67 \mathrm{~Bq}$ to $336.7 \mathrm{~Bq}$ were added to $1 \mathrm{ml}$ samples of pooled plasma. At the smallest labelled glucose concentration the recovery calculated on ten replicate experiments ranged between 90 and $95 \%$. This type of TLC method allows separation of many kinds of carbohydrates with good sensitivity (Zweig \& Sherma, 1972).

Plasma glucose concentration was determined on a Beckman Glucose Analyzer II (Beckman Instruments, Fullerton, PA, USA). The concentration of total (bound plus free) dodecanedioic acid in plasma and urine was measured by HPLC as previously described (Mingrone et al. 1991). Plasma albumin concentration was determined by a standard colorimetric method.

\section{Kinetics of dodecanedioic acid}

The kinetics of $\mathrm{C} 12$ were described by a one-compartment model. Since $\mathrm{C} 12$ binds to plasma albumin, the total plasma $\mathrm{C} 12$ concentration, $c_{t}(\mathrm{~mol} / \mathrm{l})$, can be represented by the sum of a free $\mathrm{C} 12$ fraction, $c(\mathrm{~mol} / \mathrm{l})$, and a bound $\mathrm{C} 12$ fraction. Previous results (Mingrone et al. 1994) indicate that binding follows an apparent one-step kinetic, so that the total plasma $\mathrm{C} 12$ concentration can be written

$$
c_{t}=c+n A \frac{K c}{1+K c},
$$

where $n$ is 1.57 and is the mean number of binding sites per albumin molecule and $K$ is $6.8 \times 10^{3} \mathrm{l} / \mathrm{mol}$ and is the association constant. In equation (1), $A$ denotes the mean albumin concentration in the plasma of the rats under study, which was equal to $48 \mathrm{~g} / \mathrm{l}$.

The renal excretion rate of $\mathrm{C1} 2$ was assumed to be linearly related to the concentration of free $\mathrm{C} 12$ in plasma, and the rate of tissue uptake was assumed to be saturable according to Michaelis-Menten kinetics. Since C12 was administered as an intraperitoneal bolus, the injected dose was not immediately available in the bloodstream. It was chosen to model the progressive entry of $\mathrm{C} 12$ from the peritoneum into the blood as a decreasing exponential, with unknown rate constant $\lambda(/ \mathrm{min})$. Clearly, the integral of the rate of entry over time, expressing the total amount of $\mathrm{C} 12$ moving into the blood, must equal the administered dose. Therefore, the influx $I(t)$ in $\mathrm{mol} / \mathrm{min}$ of $\mathrm{C} 12$ from peritoneum to blood takes the form $I(t)=(D \lambda) \exp (-\lambda t)$, where $D$ is the administered dose $(\mathrm{mol})$.

The kinetics of free $\mathrm{C} 12$ were then described by the following equation, which takes into account C12 binding to plasma albumin (Bertuzzi et al. 1995):

$$
V \dot{c}=\frac{1}{1+n A K /(1+K c)^{2}}\left(-\rho c-\frac{T_{m} c}{K_{m}+c}+I\right), c(0)=0,
$$

where the dot denotes differentiation with respect to time, $V$ (litres) is the distribution volume, $\rho$ the apparent renal clearance (litres/min), $T_{m}$ the maximal rate of tissue uptake $(\mathrm{mol} / \mathrm{min})$, and $K_{m}$ the uptake constant $(\mathrm{mol} / \mathrm{l})$. Model outputs are the total $\mathrm{C} 12$ concentration, $c_{t}(t)$, and the amount of $\mathrm{C} 12$ excreted in the $24 \mathrm{~h}$ urine, given by $\rho \int c(t) d t$. 


\section{Plasma glucose}

Both untreated and C12-treated rats showed a damped oscillatory pattern of plasma glucose concentration after the bolus injection of labelled glucose. In the interpretation of the tracer data, unlabelled glucose concentration could not therefore be assumed to be constant. In order to represent the behaviour of unlabelled glucose, glucose concentration data were fitted by the following oscillating function:

$$
\gamma(t)=\gamma_{b}+\delta \mathrm{e}^{-\alpha t} \sin (2 \pi t / T)
$$

where $\gamma_{b}(\mathrm{~mol} / \mathrm{l})$ denotes the central glucose concentration around which the oscillation takes place, and $\delta(\mathrm{mol} / \mathrm{l}), \alpha(/ \mathrm{min})$, and $T(\mathrm{~min})$ are unknown constants.

\section{Kinetics of $\left[{ }^{14} \mathrm{C}\right]$ glucose}

The kinetics of $\left[{ }^{14} \mathrm{C}\right]$ glucose were described by a two-compartment model (Fig. 1). Compartment 1 represents the glucose $\mathrm{C}$ in a rapidly mixing pool which includes plasma; compartment 2 represents non-glucose $\mathrm{C}$ in glucose precursors and derivatives, and is the sole source of plasma glucose since the animals were starved. The outflow from compartment 1 is divided between an irreversible loss and the inflow into the pool of glucose-precursor C. Outflow from compartment 2, due to oxidation of glucose precursors, is neglected.

Because of the observed oscillation of unlabelled glucose level, the system was not in the steady state. The rate of glucose $\mathrm{C}$ appearance in compartment 1 was assumed to be proportional to the precursor $\mathrm{C}$ amount $Q$ (mol) in compartment 2, with rate coefficient $k_{P}$ (/min), and the rates of glucose $C$ disappearance from compartment 1 were assumed to be proportional to the glucose C concentration $G(\mathrm{~mol} / \mathrm{l})$, with rate coefficients $k_{G}^{\prime}$ and $k_{G}^{\prime \prime}$ (litres/min) for the pathways of oxidation (irreversible loss) and resynthesis respectively. The mass balance equation for compartment 1 is thus

$$
V_{1} \dot{G}=-\left(k_{G}^{\prime}+k_{G}^{\prime \prime}\right) G+k_{P} Q,
$$

where $V_{1}$ (litres) is the apparent distribution volume of compartment 1 . In a non-steady state condition, the rate coefficients in equation (4) have to be considered to be timedependent.

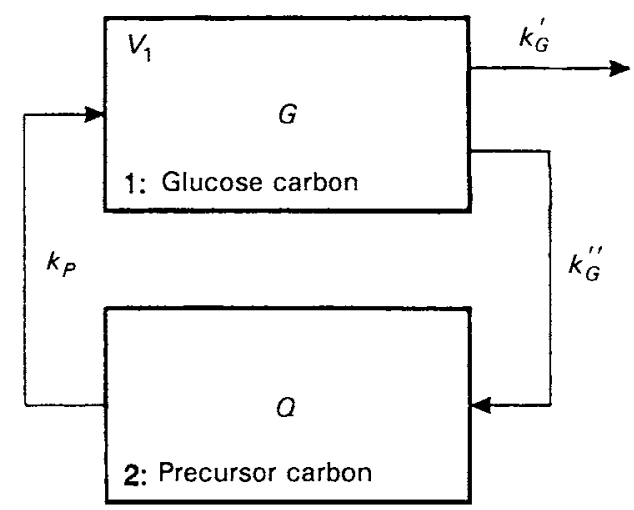

Fig. 1. Scheme of the two-pool model of glucose kinetics. For an explanation of the symbols, see above. 
Designating now by $G^{*}$ the ${ }^{14} \mathrm{C}$ concentration (expressed as $\mathrm{Bq} /$ ) in compartment 1 and by $Q^{*}$ the ${ }^{14} \mathrm{C}$ amount $(\mathrm{Bq})$ in compartment 2 , we have corresponding tracer balance equations for the two compartments

$$
\begin{gathered}
V_{1} \dot{G}^{*}=-\left(k_{G}^{\prime}+k_{G}^{\prime \prime}\right) G^{*}+k_{P} Q^{*}, G^{*}(0)=D^{*} / V_{1}, \\
\dot{Q}^{*}=k_{G}^{\prime \prime} G^{*}-k_{P} Q^{*}, Q^{*}(0)=0,
\end{gathered}
$$

$D^{*}$ being the amount of ${ }^{14} \mathrm{C}(\mathrm{Bq})$ injected as a bolus. The functions of time $k_{G}^{\prime}(t), k_{G}^{\prime \prime}(t)$, and $k_{P}(t)$, cannot all be determined from the balance equation of compartment 1 , equation (4). We thus assumed $k_{G}^{\prime}, k_{G}^{\prime \prime}$ and $Q$ to be constant in time (see pp. 151-152), so that $k_{P}(t)$ could be derived from equation (4) as

$$
k_{P}(t)=\left[V_{1} \dot{G}(t)+\left(k_{G}^{\prime}+k_{G}^{\prime \prime}\right) G(t)\right] / Q,
$$

where $G$ and $G$ are considered to be known functions of time, since they are obtained from the estimated profile of plasma glucose concentration in the form of equation (3). The equations for ${ }^{14} \mathrm{C}$ kinetics are thus obtained by substituting equation (7) in equations (5) and (6). The parameters to be estimated in equations (5)-(7) are $V_{1}, k_{G}^{\prime}, k_{G}^{\prime \prime}$, and $Q$.

\section{Estimation of unknown parameters}

Unknown parameters were estimated as means over the rat population by the method of maximum likelihood, under the assumption of normal distribution of the observations. The negative log-likelihood was minimized by a quasi-Newton algorithm and the standard errors (SE) of the estimates were determined from the inverse Hessian matrix of the negative log-likelihood computed at the optimum (Seber \& Wild, 1989).

The parameters of $\mathrm{C} 12$ kinetics, $V, \rho, T_{m}, K_{m}$, and $\lambda$, were estimated using the data of total $\mathrm{C} 12$ plasma concentration and the $24 \mathrm{~h}$ urinary excretion. The variances of the $\mathrm{C} 12$ concentration data appeared to change markedly with the time point, and were computed as sample estimates. In the fitting of unlabelled glucose concentration data by equation (3), a common coefficient of variation (CV) of the observations was instead assumed.

The estimates of glucose kinetic parameters from the labelled glucose concentration data were obtained by fitting together the data of treated and untreated animals, with a common $\mathrm{CV}$, and assuming that $V_{1}$ and $Q$ were unaffected by the treatment. Thus a total of seven parameters, i.e. the common values of $V_{1}, Q, \mathrm{CV}$, and the values of $k_{G}^{\prime}, k_{G}^{\prime \prime}$ for the treated and the untreated rats, were estimated.

\section{RESULTS}

Fig. 2 shows the experimental data of total plasma $\mathrm{C} 12$ concentration of the rats of group A, together with the concentration profile predicted by the model of equations (1)-(2). The estimates and the SE of the pharmacokinetic parameters are reported in Table 1. The excreted amount of $\mathrm{C} 12$ predicted by the model was $3.9 \%$ of the mean dose $(\bar{D}=0.8 \mathrm{mmol} / \mathrm{kg} \mathrm{BW})$, which agreed very well with the average experimental value $(0.031 \mathrm{mmol} / \mathrm{kg} \mathrm{BW})$. An alternative kinetic model with linear cell uptake was found to be inferior to the model of equation (2) by the Akaike criterion (Akaike, 1974).

Fig. 3 shows the fitting of plasma glucose data by the function in equation (3). The parameter estimates are reported in Table 2 . The Hotelling's $\mathrm{T}^{2}$ test showed a significant overall difference $(P<0.05)$ between unlabelled glucose concentration curves in treated 


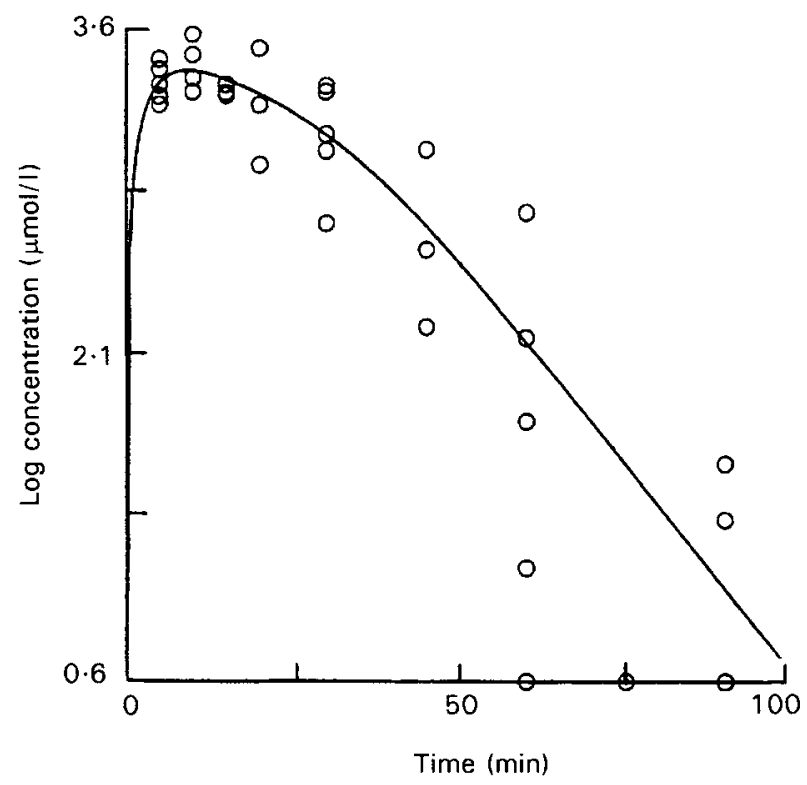

Fig. 2. Experimental data of total dodecanedioic acid concentration in plasma $v$. time $(\mathrm{O})$, and prediction by the mathematical model of equations (1)-(2) (continuous line).

Table 1. Estimates and standard errors of the kinetic parameters of dodecanedioic acid in rats of group A (thirty-two data points), obtained by equations (1) and (2)

\begin{tabular}{lcl}
\hline \hline Parameter & Estimate & SE \\
\hline$V(\mathrm{ml} / \mathrm{kg} \mathrm{BW})$ & 244.5 & 4.0 \\
$\rho(\mathrm{ml} / \mathrm{min}$ per kg BW) & 0.720 & 0.015 \\
$T_{m}(\mu \mathrm{mol} / \mathrm{min}$ per kg BW $)$ & 17.82 & 0.37 \\
$K_{m}(\mu \mathrm{M})$ & 138.5 & 8.3 \\
$\lambda(/ \mathrm{min})$ & 0.275 & 0.010 \\
\hline \hline
\end{tabular}

and untreated rats. This confirms the visual impression of a more pronounced perturbation in C12-treated rats. On the other hand, none of the parameters descriptive of the oscillating unlabelled glucose model curve were found to be individually significantly different between treated and untreated rats. Due to the Hotelling's test results, two independent fittings were performed on treated and untreated animals, and the results used separately.

The time-course of plasma $\left[{ }^{14} \mathrm{C}\right]$ glucose concentrations is shown in Fig. 4, both for control rats (group C) and for the rats treated with the intraperitoneal bolus of $\mathrm{C} 12$ (group B); the optimal curves fitted to the data according to equations (5)-(7) are also plotted in Fig. 4. Table 2 reports the estimated parameters of glucose kinetics. From the values reported in the table, estimates were obtained for the glucose pool size $V_{1} \gamma_{b}=2.30$ (SE $0.13) \mathrm{mmol} / \mathrm{kg} \mathrm{BW}$ and for the basal disappearance rate $R_{d}=\left(k_{G}^{\prime}+k_{G}^{\prime \prime}\right) \gamma_{b}$, which is equal to 82.13 (SE 18.27) $\mu \mathrm{mol} / \mathrm{min}$ per $\mathrm{kg} \mathrm{BW}$ in the untreated rats and 36.71 (SE 4.33) $\mu \mathrm{mol} / \mathrm{min}$ per $\mathrm{kg} \mathrm{BW}$ in the C12-treated rats. We notice (see Table 2) that the parameters related to the recycling of glucose $C$ have been estimated with large standard errors, especially $k_{G}^{\prime \prime}$ whose value cannot be distinguished from zero in the treated rats. The application of Wald's test (Seber \& Wild, 1989) showed that $k_{G}^{\prime \prime}$ was significantly lower in treated than in 

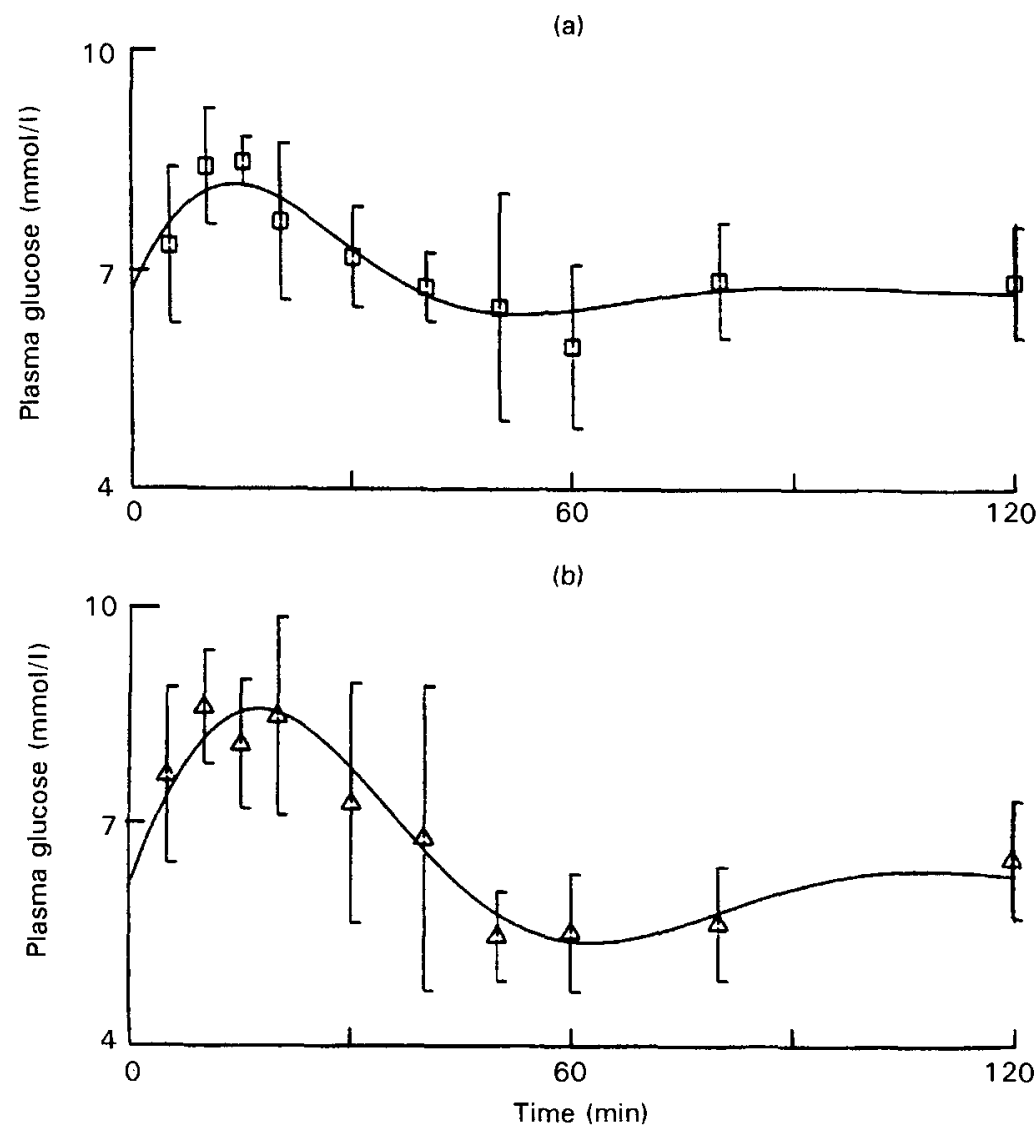

Fig. 3. Plasma glucose concentration $v$. time in (a) control rats $(\square)$, and (b) dodecanedioic acid-treated rats $(\triangle)$, and the predicted relationship from equation (3) (continuous line). Values are means of three measurements with standard deviations indicated by vertical bars.

control rats $(P<0.005)$. Thus, the rate of plasma glucose disappearance appeared to be lower in $\mathrm{C} 12$-treated rats.

\section{DISCUSSION}

In the present paper, we studied the kinetics of $\mathrm{C} 12$ in rats after an intraperitoneal bolus and the influence of acute $\mathrm{C} 12$ administration on glucose clearance. The amount of $\mathrm{C} 12$ administered as a bolus dose corresponded to $5.53 \mathrm{~kJ} / \mathrm{kg} \mathrm{BW}$, which is approximately $20 \%$ of the daily lipid-derived energy requirement in a standard total parenteral nutrition formulation (146.65 kJ/kg BW, of which $29.33 \mathrm{~kJ} / \mathrm{kg} \mathrm{BW}$ is from lipids). The loss of C12 in the urine was very small, compared with that of other shorter-chain DA. Azelaic acid, in fact, showed a very high urinary excretion ranging from 50.0 to $76.9 \%$ of the given dose (Bertuzzi et al. 1991), while sebacic acid was excreted in the urine to a lesser extent, between 16 and $46 \%$ (Mingrone et al. 1991). The estimated renal clearance of C12 was much smaller than inulin clearance in the rat (about $10 \mathrm{ml} / \mathrm{min}$ per $\mathrm{kg} \mathrm{BW}$ ), thus suggesting that $\mathrm{C} 12$ undergoes tubular reabsorption. The maximal rate of $\mathrm{C} 12$ tissue uptake $(17.8 \mu \mathrm{mol} / \mathrm{min}$ per $\mathrm{kg} \mathrm{BW})$ corresponds to a maximal energy supply of $123.7 \mathrm{~J} / \mathrm{min}$ per $\mathrm{kg}$ 
Table 2. Estimates and standard errors of the parameters of glucose kinetics in control (group $C$, twenty-four data points) and dodecanedioic acid (C12)-treated (group B, thirty data points) rats

(Parameters in the upper four rows were estimated by equation (3), and in lower four rows by equations (5)-(7))

\begin{tabular}{|c|c|c|c|c|}
\hline \multirow[b]{2}{*}{ Parameter } & \multicolumn{2}{|c|}{ Control } & \multicolumn{2}{|c|}{ C12-treated } \\
\hline & Estimate & $\mathrm{SE}$ & Estimate & SE \\
\hline$\gamma_{b}(\mathrm{mM})$ & $6 \cdot 71$ & $0 \cdot 17$ & $6 \cdot 16$ & 0.28 \\
\hline$\delta(\mathrm{mM})$ & 2.77 & $1 \cdot 39$ & $4 \cdot 11$ & 1.44 \\
\hline$\alpha(/ \mathrm{min})$ & 0.039 & 0.024 & 0.026 & $0-012$ \\
\hline$T(\min )$ & $78 \cdot 0$ & $10 \cdot 7$ & 90.6 & $7 \cdot 3$ \\
\hline$V_{1}(\mathrm{ml} / \mathrm{kg}$ body wt $(\mathrm{BW}))$ & $342.8 \dagger$ & $17 \cdot 6$ & $342.8 \dagger$ & 17.6 \\
\hline$k_{G}^{\prime}(\mathrm{ml} / \mathrm{min}$ per $\mathrm{kg} \mathrm{BW})$ & 4.76 & 0.56 & $5 \cdot 60$ & 0.28 \\
\hline$k_{G}^{\prime \prime}(\mathrm{ml} / \mathrm{min}$ per $\mathrm{kg} \mathrm{BW})$ & $7 \cdot 48$ & $2-60$ & $0.36^{* *}$ & 0.68 \\
\hline$Q(\mathrm{mmol} / \mathrm{kg} \mathrm{BW})$ & $12 \cdot 5 \dagger$ & $4 \cdot 1$ & $12 \cdot 5 \dagger$ & $4 \cdot 1$ \\
\hline
\end{tabular}

** Value was significantly different from that for the control group, $P<0.005$.

$\dagger$ Common value for control and C12-treated rats.

$\mathrm{BW}$, which is similar to the energy supplied by glucose in the control rats of the present experiments $(89.0 \mathrm{~J} / \mathrm{min}$ per $\mathrm{kg} \mathrm{BW})$, computed assuming that the oxidation rate was equal to a maximal possible value of $k_{G}^{\prime} \gamma_{b}$, corresponding to all of the non-recirculating glucose extraction from plasma.

In a previous study (Raguso et al. 1994), we demonstrated that sebacic acid infusion caused a significant reduction of insulin-mediated glucose uptake during euglycaemic hyperinsulinaemic clamp in humans. This reduction was possibly caused by intracellular substrate competition. Because $\mathrm{C} 12$ seems to be more suitable for nutritional support than sebacic acid, due to its higher net energy yield, we investigated the effect of $\mathrm{C12}$ administration on glucose kinetics in experimental animals. We performed a non-steadystate analysis on the plasma concentrations of labelled glucose, during the distribution and uptake phase of the $\mathrm{C} 12$ bolus, rather than following the more conventional approach which uses constant infusions of the substrate and of labelled glucose, followed by steadystate analysis. This choice was determined by the far simpler experimental setup, by the possibility of computing in this way the compartmental volumes of distribution, and by the possibly higher perturbating effect on glucose metabolism of the higher plasma $\mathrm{C} 12$ concentrations achieved. The interpretation of the disappearance curves of labelled glucose thus obtained requires a series of choices to be made in order to obtain an identifiable model.

(1) First of all, the hypothesis of steady state in the unlabelled glucose level had to be rejected outright, given the observed oscillation of plasma glucose concentration with an amplitude as large as about $50 \%$ of the baseline level. A likely explanation of this variable glucose time course involves the unavoidable stress to which experimental animals were subjected during the initial manipulation, with the related adrenergic response and the subsequent recovery of euglycemia. Therefore, unlabelled glucose levels during the experiment were represented by a damped sinusoidal function fitted to treated and untreated rat data.

(2) According to the literature (Baker et al. 1959; Katz et al. 1974) there is an important recycling of $\mathrm{C}$ in rats between a glucose pool and a glucose-precursor pool, so that the fundamental structure of a model for glucose kinetics would involve two compartments. A direct inflow of glucose deriving from intestinal absorption has to be considered as negligible, since the rats were starved for an adequate period of time. Under 
(a)
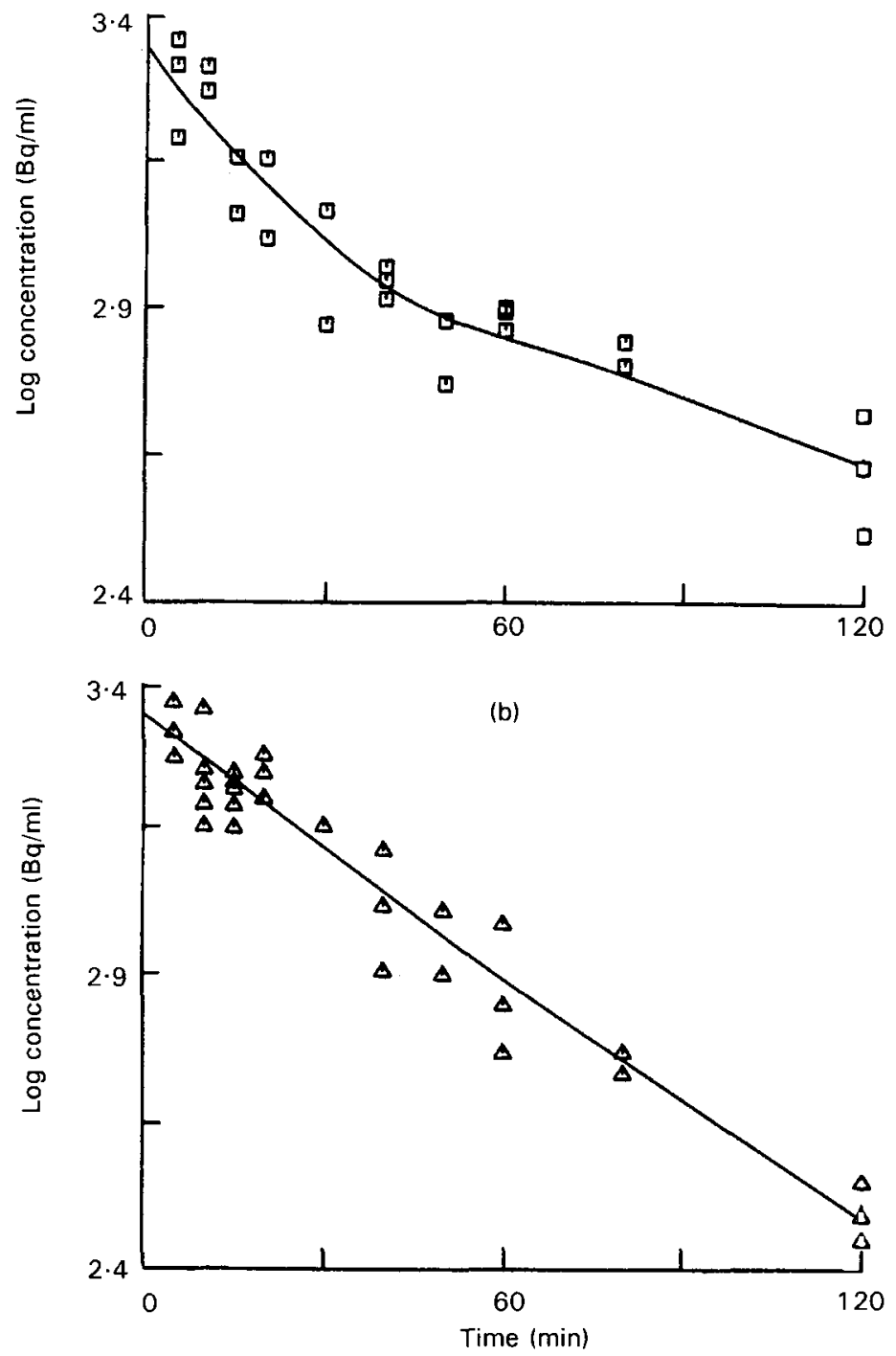

Fig. 4. Plasma $\left[{ }^{14} \mathrm{C}\right]$ glucose concentration $v$. time in (a) control rats $(\square)$, and (b) dodecanedioic acid-treated rats $(\triangle)$, and the predicted relationship by the mathematical model of equations (5)-(7) (continuous line).

the simplifying assumption that compartment inflow and outflow are determined by rate coefficients multiplying appropriate pool concentrations, three main sources of variability may underlie the non-stationary behaviour of unlabelled glucose plasma concentration: variation of the precursor pool size, variation of the outflow rate constant, or variation of the inflow rate constant.

It is likely that the precursor pool size, which includes the gluconeogenic substrates (such as glycogen, lactate, succinate) in the liver and is thus rather large (Baker et al. 1959), is little affected by variations within the time frame of the experiment. Following the adrenergic stimulus (James et al. 1986), glucose uptake increases in some tissues (notably the insulin-independent ones, like heart or brain), and decreases in other tissues 
(like the visceral organs) (Wyngaarden \& Smith, 1995), while net glucose is released into the circulation. Thus it appeared reasonable to impose, as a constant, the glucose uptake rate rather than its delivery rate.

(3) Since C12 was administered as a bolus and was cleared from plasma in about $90 \mathrm{~min}$, the possible effect of $\mathrm{C} 12$ on the kinetics of glucose would probably have had a transient character. We analysed these effects, however, as differences of time-constant model parameters between the controls and the treated rats. Moreover, in order to reduce the number of parameters to be estimated, we assumed that glucose pool volume and precursor pool size remained the same irrespective of treatment, the variations concerning mainly the flows.

With the analysis based on the described model, our estimates of glucose pool size and basal disappearance rate in control rats were in good agreement with the values reported by Baker et al. (1959), Katz et al. (1974), and Jenkins et al. (1988); see also Royle et al. (1982) for rats which were fasted for $48 \mathrm{~h}$. The administration of $\mathrm{C} 12$ drastically reduced $\mathrm{C}$ recycling between the glucose and the precursor pools, as seen also from the nearly monoexponential decay of ${ }^{14} \mathrm{C}$ concentration in plasma (Fig. 3(b)). This behaviour might be related to the fact that $\mathrm{C} 12$ supplied glucose precursors in the form of succinate and that, therefore, the quota of glucose routed to the precursor pool was correspondingly reduced. On the other hand, C12 administration did not appreciably affect the value of the rate coefficient $k_{G}^{\prime}$, which quantifies the irreversible loss from the glucose pool, and is influenced by the rate of glucose oxidation. The effect of $\mathrm{C} 12$ administration on total-body glucose uptake seems to be more pronounced than that observed after administration of triacylglycerols in rats, as reported by Jenkins et al. (1988): in fact, in order to observe a significant variation of glucose tissue uptake, the basal level of free fatty acids had to be increased fourfold. It must also be noticed that, in their study, the high level of free fatty acids was realized by a lengthy continuous infusion.

In conclusion, the present investigation suggests that $\mathrm{C} 12$ is taken up by the tissues to an extent comparable, from an energetic point of view, with that of glucose. Furthermore, C12 is likely to supply glucose precursors (Kou \& Tserng Shiow-Jen, 1991) although in a total amount which can be stoichiometrically calculated to be less than about $18 \%$ of the estimated pool size, in the extreme hypothesis of zero oxidation of $\mathrm{C} 12$-derived succinate. Therefore, if the high rate of $\mathrm{C} 12$ tissue uptake was confirmed in humans, this dicarboxylic acid could represent an interesting energy substrate, particularly in those conditions like sepsis, trauma or decompensated diabetes mellitus, where there exists an impairment of the utilization of the long-chain fatty acids administered as lipid emulsions in parenteral nutrition. In these cases, when long-chain fatty acids are used the protective mechanism of $\omega$-oxidation might be not able to prevent the increase of plasma and tissue concentrations of long-chain fatty acids which, particularly if unsaturated, are toxic for the mitochondria because of their uncoupling effect (Borst et al. 1962; Mingrone et al. 1990). The $\omega$ oxidation, indeed, allows the formation of long-chain DA which can be $\beta$-oxidized to shorter chain DA which are more soluble in water and therefore can be partially excreted with urine.

\section{REFERENCES}

Akaike, H. (1974). A new look at the statistical model identification. IEEE Transactions on Automatic Control AC-19, 716-723.

Baker, N., Shipley, R. A., Clark, R. E. \& Incefy, G. E. (1959). $\mathrm{C}^{14}$ studies in carbohydrate metabolism: glucose pool size and rate of turnover in the normal rat. American Journal of Physiology 196, 245-252. 
Bertuzzi, A., Gandolfi, A., Salinari, S., Mingrone, G., Arcieri-Mastromattei, E., Finotti, E. \& Greco, A. V. (1991). Pharmacokinetic analysis of azelaic acid disodium salt. Clinical Pharmacokinetics 20, 411-419.

Bertuzzi, A., Mingrone, G., Gandolfi, A., Greco, A.. V. \& Salinari, S. (1995). Pharmacokinetic analysis of dodecanedioic acid in humans from bolus data. Journal of Parenteral and Enteral Nutrition 19, 498-501.

Bjorkhem, I. (1978). On the quantitative importance of $\omega$-oxidation of fatty acids. Journal of Lipid Research 19 , 585-590.

Borst, P., Loos, J. A., Crist, E. J. \& Slater, E. C. (1962). Uncoupling activity of long-chain fatty acids. Biochimica et Biophysica Acta 62, 509-518.

Greco, A. V. \& Mingrone, G. (1995). Dicarboxylic acids, an alternate fuel substrate in parenteral nutrition: an update. Clinical Nutrition 14, 143-148.

James, D. E., Burleigh, K. M. \& Kraegen, E. W. (1986). In vivo glucose metabolism in individual tissues of the rat. Interaction between epinephrine and insulin. Journal of Biological Chemistry 261, 6366-6374.

Jenkins, A. B., Storlien, L. H., Chisholm, D. J. \& Kraegen, E. W. (1988). Effects of nonesterified fatty acid availability on tissue-specific glucose utilization in rats in vivo. Journal of Clinical Investigation 82, $293-299$.

Katz, J., Dunn, A., Chenoweth, M. \& Golden, S. (1974). Determination of synthesis, recycling and body mass of glucose in rats and rabbits in vivo with ${ }^{3} \mathrm{H}$ - and ${ }^{14} \mathrm{C}$-labelled glucose. Biochemical Journal 142, 171-183.

Kou, Y. \& Tserng Shiow-Jen, J. (1991). Metabolic conversion of dicarboxylic acids to succinate in rat liver homogenates. Journal of Biological Chemistry 266, 2924-2929.

Leighton, F., Bergseth, S., Rortveit, T., Christiansen, E. N. \& Bremer, J. (1989). Free acetate production by rat hepatocytes during peroxisomal fatty acid and dicarboxylic acid oxidation. Journal of Biological Chemistry 264, 10346-10350.

Lindstedt, S., Norberg, K., Steen, G. \& Wahl, E. (1976). Structure of some aliphatic dicarboxylic acids found in the urine of an infant with congenital lactic acidosis. Clinical Chemistry 22, 1330-1338.

Mingrone, G., Greco, A. V. \& Arcieri-Mastromattei, E. (1990). Free fatty acids stimulate mucin hypersecretion by rabbit gallbladder epithelium in vitro. Clinical Science 78, 175-180.

Mingrone, G., Greco, A. V., Bertuzzi, A., Arcieri-Mastromattei, E., Tacchino, R. M., Marino, F., Finotti, E. \& Castagneto, M. (1991). Tissue uptake and oxidation of disodium sebacate in man. Journal of Parenteral and Enteral Nutrition 15, 454-459.

Mingrone, G., Greco, A. V., De Gaetano, A., Tataranni, A., Raguso, C. \& Castagneto, M. (1994). Pharmacokinetic profile of dodecanedioic acid, a proposed alternative lipid substrate for parenteral nutrition. Journal of Parenteral and Enteral Nutrition 18, 225-230.

Mingrone, G., Tacchino, R. M., Greco, A. V., Arcieri-Mastromattei, E., Marino, F., Finotti, E. \& Castagneto, M. (1989). Preliminary studies of a dicarboxylic acid as an energy substrate in man. Journal of Parenteral and Enteral Nutrition 13, 299-305.

Mortensen, P. G. \& Gregersen, N. (1981). The biological origin of ketonic dicarboxylic aciduria. In vivo and in vitro investigations of the $\omega$-oxidation of $\mathrm{C} 6-\mathrm{C} 10$-monocarboxylic acids in unstarved, starved and diabetic rats. Biochimica et Biophysica Acta 666, 394-404.

Pettersen, J. E. \& Aas, M. (1973). ATP-dependent activation of dicarboxylic acids in rat liver. Biochimica et Biophysica Acta 326, 305-313.

Raguso, C., Mingrone, G., Greco, A. V., Tataranni, P. A., De Gaetano, A. \& Castagneto, M. (1994). Dicarboxylic acids and glucose utilization in humans: effect of sebacate. Journal of Parenteral and Enteral Nutrition 18, 9-13.

Royle, G. T., Wolfe, R. R. \& Burke, J. F. (1982). Glucose and fatty acid kinetics in fasted rats: effects of previous protein intake. Metabolism 31, 279-283.

Seber, G. A. F. \& Wild, C. J. (1989). Nonlinear Regression. New York: Wiley.

Verkade, P. E. \& Van der Lee, J. (1934). Researches on fat metabolism II. Biochemical Journal $28,31-40$.

Wada, F. \& Usami, M. (1977). Studies on fatty acid omega-oxidation. Antiketogenic effect and gluconeogenicity of dicarboxylic acids. Biochimica et Biophysica Acta 487, 261-268.

Wyngaarden, J. B. \& Smith, L. H. (editors) (1995). Cecil Textbook of Medicine. Philadelphia: W. B. Saunders Company.

Zweig, G. \& Sherma, J. (editors) (1972). CRC Handbook of Chromatography: General Data and Principles, vol. 1, pp. 462-463. Boca Raton, FL: CRC Press. 